\title{
MULTI-SCALE MONITORING OF LANDSCAPE CHANGE AFTER THE 2011 TSUNAMI
}

\author{
K. Hara ${ }^{\text {a }}$, , Y. Zhao ${ }^{\text {a, b }}$, I. Harada ${ }^{\text {a }}$, M. Tomita ${ }^{\text {a }}$, J. Park ${ }^{\text {a }}$, E. Jung ${ }^{\text {a }}$, N. Kamagata ${ }^{\text {c }}$, Y. Hirabuki ${ }^{\text {d }}$ \\ a Department of Informatics, Tokyo University of Information Sciences, Chiba, 2658501 Japan - \\ (hara, yzhao, iharada, tomita, amon)@ rsch.tuis.ac.jp \\ ${ }^{\mathrm{b}}$ R\&D Center, Pasco Corporation, Higashiyama, Meguro-ku, Tokyo 1530043 Japan - yoiazh3363@ @asco.co.jp \\ ${ }^{c}$ Remote Sensing Unit, Kokusai Kogyo Co., Ltd., Fuchu, Tokyo 1830057 Japan - noritoshi_kamagata@kk-grp.jp \\ ${ }^{d}$ Department of Regional Design, Tohoku Gakuin University, Sendai 9813139, Japan - yhira@ mail.tohoku-gakuin.ac.jp
}

\section{Commission VIII, WG VIII/1}

KEY WORDS: Tsunami, Landscape change, Monitoring, Multi-scale, Great East Japan Earthquake

\begin{abstract}
:
The Great East Japan Earthquake (magnitude 9.0; occurred on $11^{\text {th }}$ March 2011) and subsequent huge tsunami caused widespread damage along the Pacific Ocean coast of eastern Honshu, Japan. This research utilizes multi-resolution remote sensing images to clarify the impact on landscapes caused by this disaster, and also to monitor the subsequent survival and recovery process in the Sendai Bay region. The coastal landscape in the target area features a narrow strip of coastal sand barrier, historically stabilized by planted pine groves; backed by a low-lying plain that has traditionally been diked and converted to irrigated rice paddies. Farmsteads on the flat alluvial plain are surrounded by groves called "Igune", consisting primarily of conifers. MODIS data (250 m resolution) were employed to map the overall extent of inundation and damage on the regional landscape scale. The major damage caused by the tsunami, destruction of coastal pine forests and inundation or rice paddies on the plain, was identified at this level. Progressively finer scale analysis were then implemented using SPOT/HRG-2 (10 m resolution) data; GeoEye-1 fine resolution data (0.5 m) and very fine resolution aerial photographs $(10 \mathrm{~cm})$ and LiDAR. These results demonstrated the minute details of the damage and recovery process. Some patches of pine forest, for example, were seen to have survived, and some coastal plant communities were already recovering only a year after the disaster. Continuous monitoring using field work and remote sensing is required for balanced regional strategies that provide for economic and social recovery and as well as restoration of vegetation, biodiversity and vital ecosystem services.
\end{abstract}

\section{INTRODUCTION}

The Great Eastern Japan Earthquake and subsequent tsunami, which struck on the 11th of March, 2011, caused enormous damage to vegetation communities along the Pacific Ocean side of the Tohoku Region (Hara \& Higuchi, 2013; Zhao et al., 2013; Hara, 2014; Himiyama et al., 2014). Earthquakes and tsunami of this scale are relatively rare on the Sendai Plain, occurring on a cycle of several hundred to a thousand years. These sort of 'large and infrequent disturbance' (Tomita et al. 2014) have a special impact on regional ecosystems.

Despite the severity of the tsunami and the enormous scale of the disturbance, many plant communities in the stricken area have been recovering remarkably (Kanno et al., 2014; Oka \& Hirabuki, 2014). On the other hand, the coastal zone includes many ports and populated areas; and reconstruction works have been preceding at a fast pace. This is especially so in the Sendai Bay area, which contains Sendai, the largest city in the region, as well as Sendai Airport and other vital infrastructure facilities. In these areas, infrastructure reconstruction must be balanced with recovery of plant communities and conservation of biodiversity and ecosystems. To accomplish this, timely and efficient monitoring of changes in vegetation and land cover is required. This research is designed as a first step in using multi-scale remote sensing data a means for meeting these requirements.

\section{STUDY AREA AND METHODS}

\subsection{Study area}

The research was implemented in the disaster-stricken area of Sendai Bay (Figure 1).

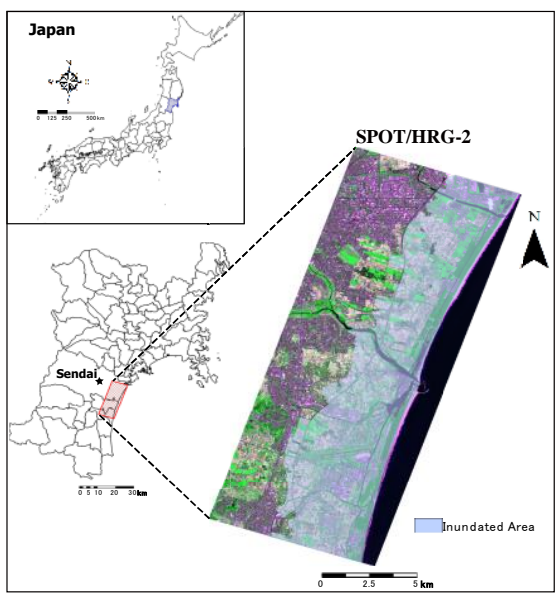

Figure 1. Map of Tohoku Region showing Sendai Bay study area SPOT/HRG-2 image shows stretch of coastal plain inundated by the tsunami. (C) CNES 2010-2011, Distribution Astrium Service/Spot Image S.A.

\footnotetext{
* Corresponding author
} 
The target area focused on Sendai Bay in Miyagi Prefecture The coastal landscape at this spot consists of a long thin sand barrier, originally stabilized by planted groves of Japanese native pine species (Pinus thunbergii and Pinus densiflora); behind which stretches a low-lying coastal plain that has historically been diked and converted to irrigated rice paddies. The flat rice paddies are dotted with individual farmsteads protected by groves of conifers (primarily Cryptomeria japonica) known as "Igune". The large city of Sendai occupies the northern part of the coastal plain.

\subsection{Methods}

Remote sensing data of four different spatial resolutions; broadscale $(250 \mathrm{~m}$ resolution Terra/MODIS); medium scale $(10 \mathrm{~m}$ resolution SPOT/HRG-2); fine scale (0.5m resolution GeoEye- 1$)$ and very fine-scale $(10 \mathrm{~cm}$ resolution digital aerial photographs and LiDAR); were employed successively to evaluate changes in vegetation and land cover caused by the earthquake and tsunami, as well as monitoring the process of vegetation recovery and the ongoing effects of reconstruction projects. The level of analyses starts with an entire regional landscape, then is step by step finetuned to the level of individual habitats and tree groves.

\section{RESULTS AND DISCUSSION}

\subsection{Broad-scale analysis}

Terra/MODIS data acquired and archived at Tokyo University of Information Sciences were utilized. Monthly composite images for the target area were constructed for September of 2001, well before the disaster; and September of 2013, two and a half years afterwards. The results are shown as natural colour images in Figure . 2. Even at this wide-scale level of resolution, which includes an entire regional landscape in a single image, loss of coastal pine groves and inundation of rice paddies on the plain can be identified.

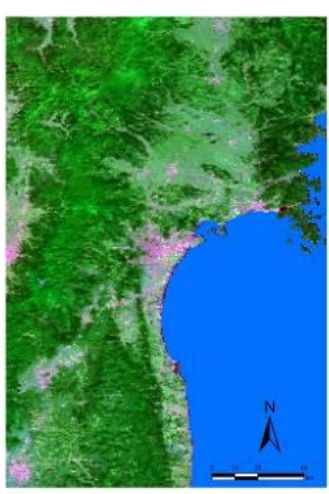

(a) 2001

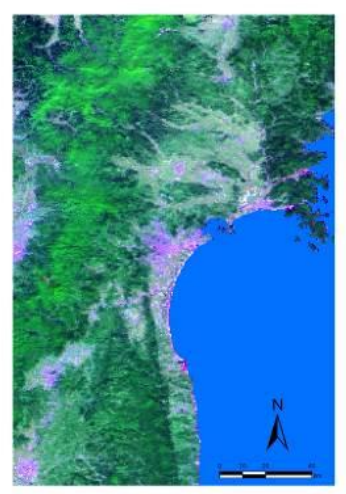

(b) 2013
Figure 2(a), (b). Natural colour images derived from monthly composite Terra/MODIS data for September of 2001 (a: left) and September of 2013 (b: right). R:G:B=1:6:3
The MODIS data was also used to construct NDVI images for a smaller section of the target area. The images were constructed for the summer months, when vegetation was at a maximum. NDVI images for 2010, 2011, 2012 and 2013 are presented in Figure 3. At this level of resolution, the great reduction in vegetation, especially on the coastal plain, is clearly visible. The images for 2012 and 2013, however, show that vegetation has been slowly recovering in the years after the disaster. In this area the huge tsunami swept over the sand barrier, completely inundating the rice paddies on the back plain. Over the past several years, however, reconstruction projects have been reclaiming some of the inundated paddies.

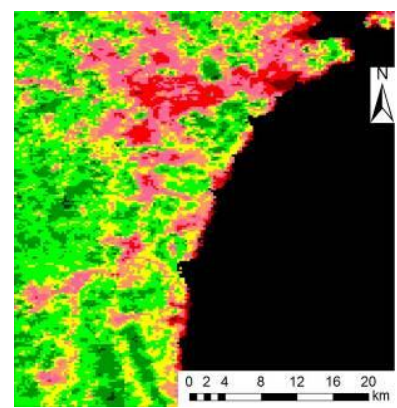

(a) 2010

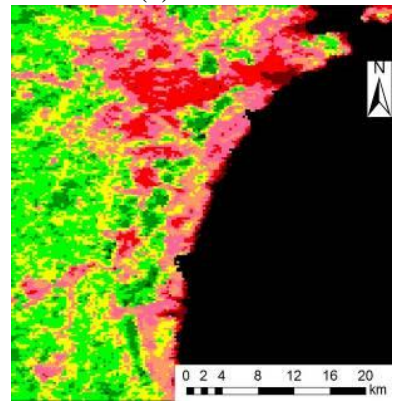

(c) 2012

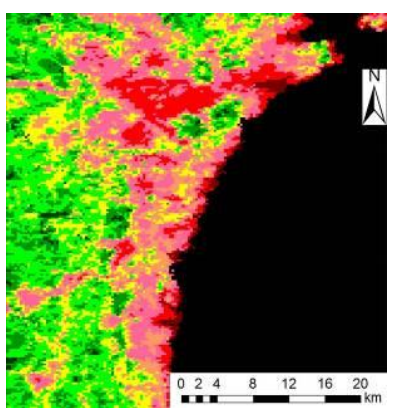

(b) 2011

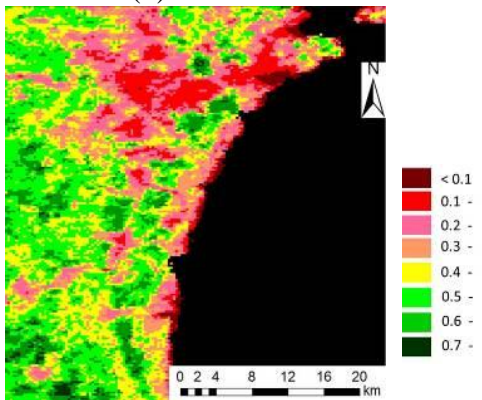

(d) 2013
Figure 3(a), (b), (c), (d). NDVI images constructed from Terra/MODIS data for the Sendai Bay area. (a): 2010, (b): 2011, (c): 2012 and (d) 2013.

\subsection{Medium-scale analysis}

Medium resolution SPOT/HRG-2 images were used to more closely evaluate the extent of inundation and changes in land cover for an even smaller section of the Sendai Bay coastline, around the mouth of the Natori River. The images before and after the disaster are shown in Figure 4(a). The loss of pine forest along the coast, as well as the inundation of paddies on the coastal plain, can be clearly seen.

A land cover classification was implemented on the same data. Six land cover categories were established: Forest; Grass/Scrub; Paddy; Urban Area; Open Water; and Bare Land (including sand dunes). The results of the classification are shown in Figure 4(b). After the disaster almost all of the Forest area along the coast, as well as most of the Paddy area on the plain, have changed to Grass/Scrub. 


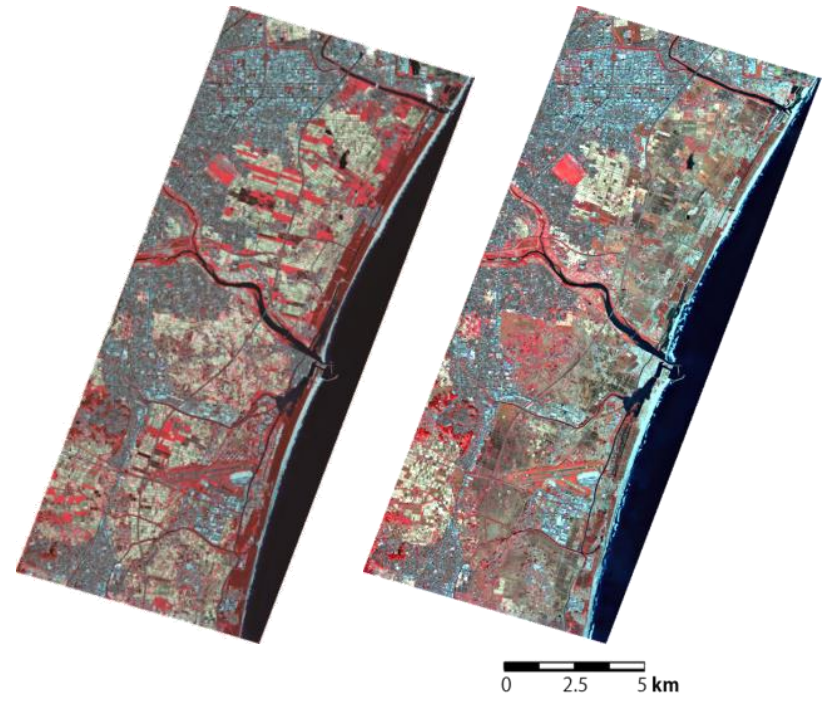

Figure 4(a). SPOT/HRG-2 images for the Sendai Bay area, before (left: $2^{\text {nd }}$ September 2010) and after (right: $2^{\text {nd }}$ November 2011) the disaster. R:G:B=3:2:1 (C) CNES 2010-2011, Distribution Astrium Service/Spot Image S.A.

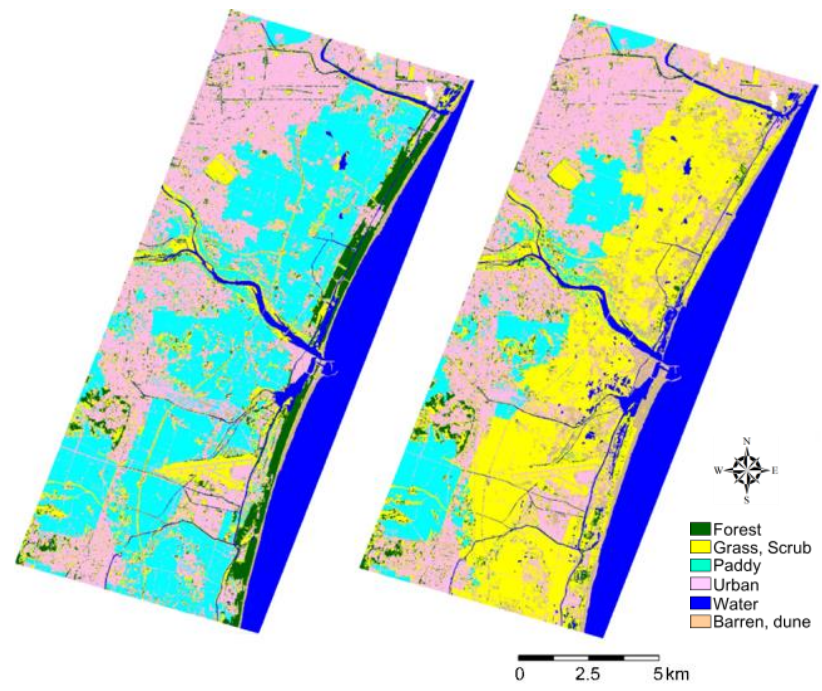

Figure 4(b). Results of land cover classification of SPOT/HRG-2 images for the Sendai Bay area, before (left: $2^{\text {nd }}$ September 2010) and after (right: $2^{\text {nd }}$ November 2011) the disaster.

\subsection{Fine-scale analysis}

The extent of damage to this area, as well as the process of recovery, was analysed in finer detail using $1 \mathrm{~m}$ resolution GeoEye-1 images acquired for $4^{\text {th }}$ April 2010 and $24^{\text {th }}$ March 2011. Figure 5(a) shows that same area of coast analysed in section 3.2. Again the loss of the coastal pine forests can be easily identified. The fine-scale resolution of these images, however, allows the research to zoom in on very small sections of the target area. Figure 5(b) shows images extracted for a section of the coastal pine grove. The pre-disaster image at left shows the extent of the pine forest before the disaster. The pines were originally planted along a banked canal constructed parallel to the coast, and the first plantings date back nearly 400 years. At this resolution it can be seen that the pines were distributed not only on the canal banks, but also in narrow swaths on both the landward and seaward sides of the canal.

In broader resolution images the pine groves appear to have been completely destroyed. Very close up, however, it becomes in the right-side image that damage to the pine forests varied greatly among micro-habitats.
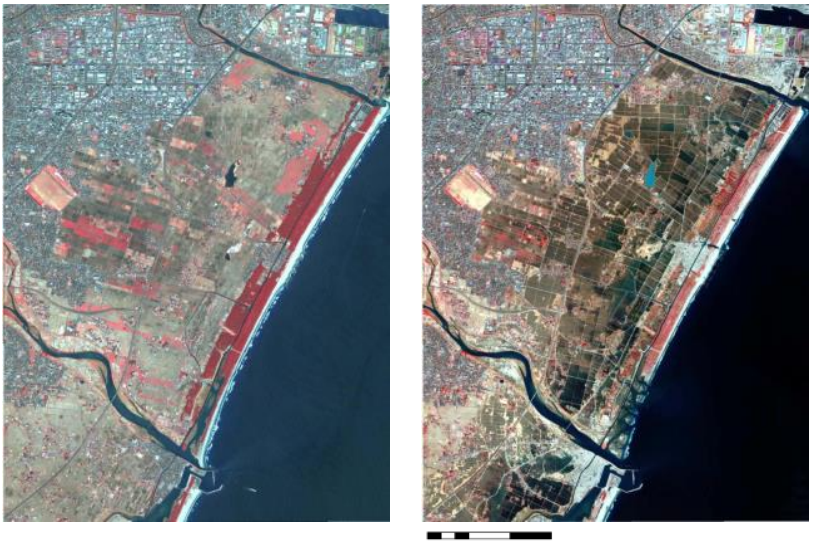

Figure 5(a). GeoEye-1 images for a section of Sendai Bay coastline, acquired for $4^{\text {th }}$ April 2010 (left) and $24^{\text {th }}$ March 2011 (right). R:G:B=4:3:2 (C) GeoEye/JSI
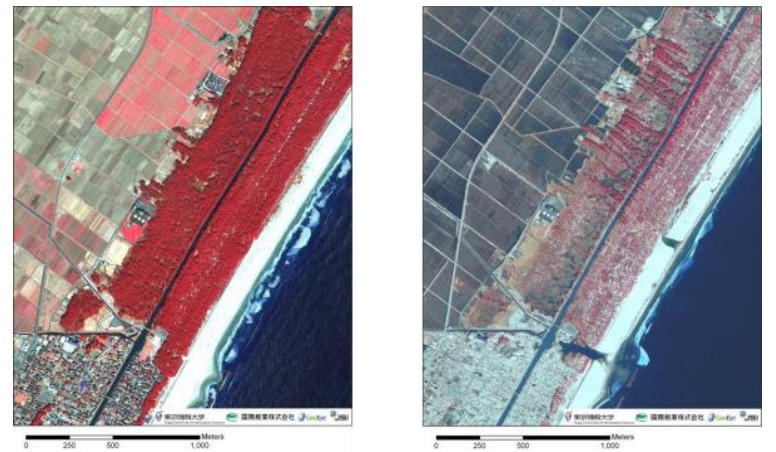

Figure 5(b). Zoom-in view of above GeoEye-1 images. $\mathrm{R}: \mathrm{G}: \mathrm{B}=4: 3: 2$ (After Hara and Higuchi, 2013)

\subsection{Very fine-scale analysis}

Very fine resolution $(10 \mathrm{~cm})$ aerial photographs (DMC-2) were employed to clarify the patterns of destruction and survival among the pine trees, as well as the process of recovery after the disaster. Figure 6(a) shows a close-up image of the damage soon after the disaster $\left(31^{\text {st }}\right.$ March 2011). According to researches conducted by Hirabuki et al. (2011) and Tomita et al. (2014), many of the shorter pines seaward of the canal were bent over or broken by the force of the tsunami, while taller trees on the high banks along the canal survived much better. Landward of the canal, strips of pine forest survived in narrow comb-like strips running perpendicular to the coast and direction of the wave. This area landward of the canal was originally a low-lying back marsh that had been filled in and planted with pines. Pinus thunbergii and Pinus densiflora naturally prefers to sink deep roots into dry sandy soils. In this thick marshy soil, however, the roots were unable to penetrate downwards, and were forced to spread outwards. This reduced the stability of the trees and their ability to withstand the force of the wave. The precise reason for 
the peculiar comb-like pattern of remaining trees, however, is still under investigation. The area covered by the data is a small section of the coastal barrier.

Figures 6(c) through 6(d) show the same area at intervals following the disaster. These images show that most of the pine forest patches that survived the tsunami were still viable more than a year later, on $10^{\text {th }}$ July 2012 . In addition, by this time the herbaceous layers dominated by Robinia pseudoacacia had already started to recover. A vegetated patch seen on the sandy backshore is expanded in Figure 6(e). This patch, dominated by Rosa rugosa represents sandy beach plant community that is beginning to recover.

The extent of destruction, survival and recovery of the pine grove can also be monitored in fine detail using shadow maps compiled from LiDAR data. In Figure 7, for example, a LiDAR image is compared with a photograph of the same area. The photo shows the tree, shrub and herbaceous layers all together, but the LiDAR image is able to pick out just the tree layer (Kamagata et al. 2013).

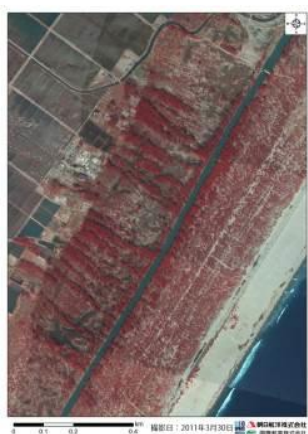

(a)

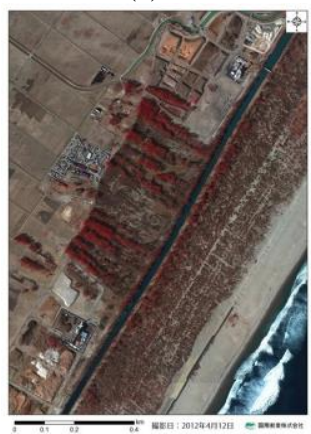

(c)

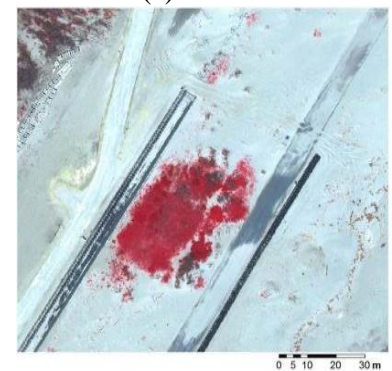

(e)

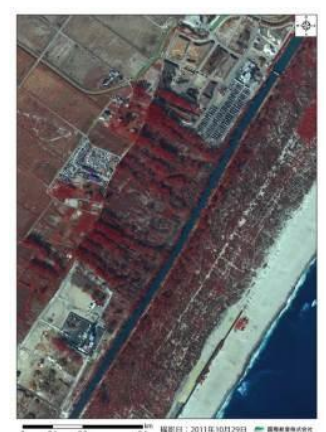

(b)

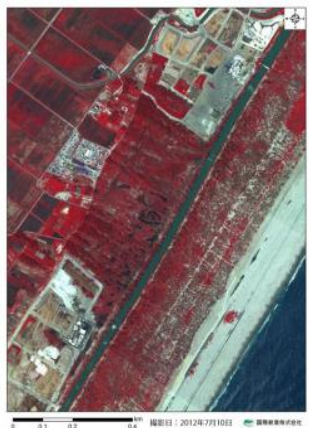

(d)

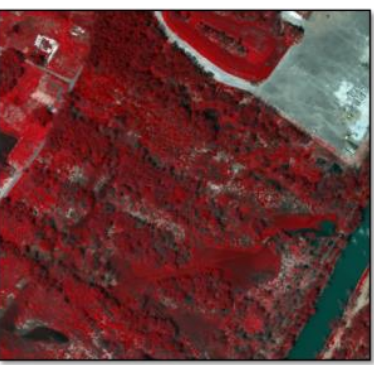

(a)

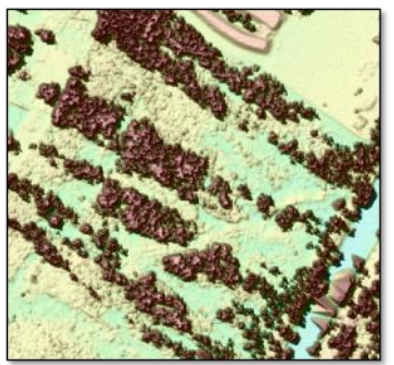

(b)
Figure 7(a), (b). Comparison of aerial photograph (a: left) with LiDAR image (b: right). Both images acquired for $10^{\text {th }}$ July 2012.

\section{CONCLUSION}

The results of this research show that multi-scale remote sensing data provides an ideal tool for evaluating the damage caused by large infrequent disturbances, as well as monitoring the subsequent processes of survival and recovery. Varying the scale allows the research to fine-tune the level of analyses, from that of an entire regional landscape or ecosystem down to patterns of survival and recovery of individual habitats and tree groves. The sandy coastal habitats of the Sendai Bay region not only support unique forms of vegetation, but also serve as vital ecotones connecting the marine and terrestrial ecosystems. In addition, the igune farmstead groves on the coastal plain function as 'stepping stones' in an ecological corridor running from the shore up into the forested hills further inland. The damage to these precious vegetation communities can be clearly seen in the remote sensing images and classifications employed here. It should be kept in mind, however, that the tsunami occurred in early spring, when most herbaceous plants had yet to emerge, and deciduous shrubs were still dormant. The damage would thus have been even greater had the disaster fallen later in the season. Some coastal vegetation communities dominated by herbaceous plants and deciduous shrubs had already recovered substantially by the following year, as could be seen in the very fine resolution aerial photographs.

Remote sensing images are widely and readily available in various resolutions and at different intervals. In the future remote sensing analyses should play a major role in integrating reconstruction of infrastructure and future disaster prevention projects with the needs for conservation of biodiversity, ecosystems and historic patterns of relating to nature.

\section{ACKNOWLEDGEMENTS}

This research was supported by JSPS KAKENHI 24510332, 24810024, 25830153 and the Environment Research and Technology Development Fund (1-1405) of Ministry of Environment, Japan.

Figure 6(a), (b), (c), (d). Very fine resolution $(10 \mathrm{~cm})$ aerial photographs (DMC-2) for a section of Sendai Bay coastline. Photos taken on $31^{\text {st }}$ March 2011 (a), $29^{\text {th }}$ October 2011 (b), $12^{\text {th }}$ April 2012(c), $10^{\text {th }}$ July 2012 (d).

Figure 6(e). Zoom-in view of Figure 6(d), showing patch of recovering coastal vegetation. 


\section{REFERENCES}

Hara, K. 2014. Damage to coastal vegetation due to the 2011 tsunami in Northeast Japan and subsequent restoration process: analyses using remotely sensed data. Global Environmental Research, 18 (1), pp.27-34.

Hara, K. and Higuchi, H. 2013. Effects of the 2011 Great East Japan Earthquake and Tsunami disaster on ecosystems. Global Environment (Chikyu Kankyo), 18(1), pp. 23-33. (in Japanese with English abstract)

Himiyama, Y., Watanabe T. and Hara, K. 2015. The impact of the Great East Japan Tsunami of 2011 on land use. Global Environmental Research, 18 (2), pp. 191-206.

Hirabuki, Y., Tomita, M., Kanno, H. and Hara, K. 2011. Impact of Great East Japan earthquake and subsequent tsunami on vegetation in the sand-dune coastal ecotone along the shores of Sendai Bay, in the Tohoku District of northern Japan. Yakuyoshokubutu-kenkyu, 33(2), pp. 45-57. (In Japanese)

Kamagata, N., Akamatsu, Y., Hara, K., Tomita, M. and Hirabuki, Y. 2013. Environmental monitoring of areas damaged by Great East Japan Earthquake and subsequent tsunami using digital aerial photographs and airborne LiDAR: A case study of the Sendai Bay coastal forests. Landscape Ecology and Management, 18(1), pp. 29-34. (In Japanese)

Kanno,H., Hirabuki, Y., Sugiyama, T., Tomita, M. and Hara, K. 2014. Vegetation change in various coastal forest habitats after a huge tsunami: a three-year study. Japanese Journal of Conservation Ecology, 99, pp. 201-220. (in Japanese with English abstract)

Oka, K. and Hirabuki, Y. 2014. Revegetation of coastal plants damaged by the 2011 Tohoku tsunami. Japanese Journal of Conservation Ecology, 99, pp.189-199. (in Japanese with English abstract)

Tomita, M., Hirabuki, Y., Kanno, H. and Hara, K. 2014. Influence of tsunamis as large, infrequent disturbances on tree communities of coastal forest. Japanese Journal of Conservation Ecology, 99, pp.163-176. (in Japanese with English abstract)

Zhao, Y., Tomita, M. and Hara, K. 2013. Landscape change analysis before and after the earthquake disaster in Sendai coastal area by using SPOT satellite data. Journal of Nature Restoration and Conservation. 6(1), pp. 43-49. (in Japanese with English abstract) 